J. Clin. Chem. Clin. Biochem.

Vol. 26, 1988, pp. $187-194$

(C) 1988 Walter de Gruyter \& Co.

Berlin - New York

\title{
Surface Tension Properties of Human Urine: Relationship with Bile Salt Concentration ${ }^{1}$ )
}

By C. O. Mills, E. Elias

Department of Internal Medicine, Queen Elizabeth Hospital, Birmingham, U.K.

G. H. B. Martin, M. T. C. Woo

Red Roofs, Nuneaton, U.K. and

A. F. Winder

Department of Chemical Pathology, Leicester Royal Infirmary, U.K.

(Received January 8/August 8, 1987//January 22, 1988)

Summary: The surface tension of urine has been simply and rapidly measured using two methods, the DuNouy ring detachment method and the Wilhelmy blade immersion method. The methods agree, the correlation coefficient, r, was 0.992 .

The effect of ageing of the surface, of storage, of temperature, $\mathrm{pH}$, dilution and albumin on urine surface tension are described.

Volume corrected 24 hour urine surface tensions from 6 volunteers over 12 or more days showed variations between individuals of mean surface tensions of $6 \mathrm{mN} / \mathrm{m}$ (S.D. $\pm 2.16 \mathrm{mN} / \mathrm{m}$ ). This suggests individual variation in excretion of surface active agents, probably bile salts.

This was confirmed by further studies which showed that:

1. Surface tension of urines and rediluted extracts were not significantly different when amphiphilic and hydrophobic solutes including bile salts were extracted from urine and subsequently rediluted in water of the same volume.

2. Bile salt concentration in urine measured by RIA and by enzymatic spectrofluorometric methods correlated well with urine surface tension, $\mathrm{r}=-0.91$, and $\mathrm{r}=-0.60$.

3. Molecular surface area for urinary surfactant was $79 \AA^{2}$ similar to pure conjugated bile salt solutions calculated from dilution studies.

We conclude that the main determinant of urine surface tension is bile salt concentration.

\section{Introduction}

Physical properties of human body fluids, such as specific gravity of urine and plasma viscosity, have been studied intensively. The measurement of surface tension of urine and blood has however received less attention. The surface tension $(\gamma)$, is the force per unit length exerted by a liquid measured in millinewtons per metre $(\mathrm{mN} / \mathrm{m})$, or dynes per centimetre. It is reduced by the presence of surface active agent.

1) Funding Organisations:

West Midlands Regional Health Committee Research Fund Coventry and Warwickshire Postgraduate Medical Centre Research Fund, Rudolph Friedlaender Memorial Fund for General Practice

C.O.M. is funded by the Medical Research Council, U.K. 
DuNouy (1) noted a reduction in surface tension with time and repeated measurement in serum and this observation has been confirmed recently by Mottaghy \& Hahn (2).

This ageing of surfaces is found after pouring simple solutions of surface active agents where excess surface active molecules continue to aggregate at the surface until an equilibrium state is reached, with a lower but static surface tension.

The number of molecules of surface active agent at this surface (surface excess concentration) is less than one ten thousandths of the number of surface active molecules in the bulk liquid. Thus surface tension measurement gives an indication of bulk surface active agent concentration assuming that there is a single predominant surface active agent in dilute solution. (Bangham, O. (1986), personal communication).

Padday (3) reported that of the various methods available for measuring surface tension of solutions where ageing is suspected capillary height, drop weight, maximum bubble pressure and DuNouy ring methods are less suitable than the sessile drop profile and Wilhelmy plate methods; measurements which involve rupture of the surface may lead to serious errors (4).

The aim of this study was to compare the use of the $4 \mathrm{~cm}$ circumference platinum DuNouy ring detachment method with a $2 \mathrm{~cm}$ platinum blade immersion method, the former being a 'semidynamic', and the latter, a static or equilibrium technique of measurement (the Dognon \& Abibrat modification of the Wilhelmy method) (5).

We also wished to investigate if ageing of surface, storage, temperature, dilution, $\mathrm{pH}$ and albumin influenced urine surface tension and whether 24 hour volume corrected urine samples varied significantly in surface tension. We further wished to explore the proposition that the surfactants responsible for surface tension changes in physiological urine are bile salts as indicated by Hay's test (6).

\section{Materials and Methods}

A 'Direct Pull' Surface and Interfacial Tensiometer (White Electrical Instruments, Malvern U.K.) was used. This is calibrated $0-1.12$ Newtons/metre giving a direct 'read off in dynes/cm or milliNewtons/metre $(\mathrm{mN} / \mathrm{m})$, using a standard $4 \mathrm{~cm}$ circumference platinum ring. Platinum blades $(4.001 \mathrm{~cm}$ and $3.957 \mathrm{~cm}$ provided by Dr J. F. Padday, Interface Science Laboratory, Research Division, Kodak Ltd) were used for comparison with the ring. Purified water (B.P., Eur.P.), and FC 43 (perfluorotributylamine, $3 \mathrm{M}$ Company, Atherstone, U.K.), surface tensions 72.6 and $16.1 \mathrm{mN} / \mathrm{m}$ at $20^{\circ} \mathrm{C}$ respectively were used for calibration.
For readings using the ring detachment method $(1,2)$ the procedure described in the manufacturers instructions were used.

The detachment force is related to the surface tension by the expression $\gamma=\mathrm{BF} / 4 \pi \mathrm{r}$, where $\mathrm{F}=$ pull on the ring and $\mathrm{r}=$ radius of the ring, and $B=a$ correction factor. Values of $B$ have been tabulated by Harkins \& Jordan (7).

i

The platinum blade was hung and the balance adjusted so that it weighed 'zero'. A urine surface was 'introduced' up to the blade, and at contact the blade was drawn about $0.5 \mathrm{~cm}$ into the fluid. Traction was then applied to the blade until the balance arm was level again, and therefore the lower edge of the blade was exactly level with the surface of the fluid; the traction force was directly recorded. For this method, $\gamma=F / 2$ $(X+Y)$ where $X=$ length and $Y=$ the thickness of the blade; there are no buoyancy corrections.

Precision and ageing comparisons used the ring and blade methods as described above. For storage and temperature studies blade method was used.

For the temperature studies the blade continuous immersion method was used. The bulb of mercury thermometer was immersed through the urine surface, the urine being contained in a standard glass measuring pot, itself immersed in a water bath.

In order to study the effect of $\mathrm{pH}$ on urine surface tension acid urines of different surface tension were made alkaline by dropwise addition of sodium hydroxide $0,89 \mathrm{~mol} / \mathrm{l}$, surface tension $60 \mathrm{mN} / \mathrm{m}$, using a '3D' $\mathrm{pH}$ meter (Corning, Halstead, Essex) with the probe immersed in the urine, the blade immersion technique was employed. It was not possible to measure urine of $\mathrm{pH}<6$ because it contained large amounts of buffer which required unacceptable volumes of alkali to shift $\mathrm{pH}$ significantly; it was usually of surface tension $<60 \mathrm{mN} / \mathrm{m}$.

For dilution studies urine was serially diluted using a $0.1 \mathrm{~mol} / \mathrm{l}$ sodium phosphate buffer of surface tension $73.2 \mathrm{mN} / \mathrm{m}$, and $\mathrm{pH}$ 7. The ring detachment and blade immersion methods were both used.

Human albumin B.P. ('Albuminar' 20, Armour Pharmaceuticals Co., Eastbourne, U.K.) was added to human urine of known surface tension to produce albumin in urine of $0.1,0.3$ and $1.0 \mathrm{mmol} / 1$. Surface tensions were measured using the blade method at 5 minute intervals until the same reading $(57.2 \pm 0.2$ $\mathrm{mN} / \mathrm{m}$ ) was obtained for 3 successive 5 minute intervals. The urine was then checked using Albustix' (Ames Co., Slough, U.K.) to confirm the amount of albumin was 'negätive', 'trace' and ' + ' respectively for the samples.

Using reagent grade chemicals, solutions of the major solutes present in urine at maximum concentration, were prepared in purified water and their surface tension measured at $20^{\circ} \mathrm{C}$ using the ring method (tab. 1).

Six healthy adult male volunteers aged 29 to 43 collected 24 hour urine samples daily for a minimum of 12 days. Diet was unrestricted. The urine samples were diluted up to $1920 \mathrm{ml}$ with purified water, and $20 \mathrm{ml}$ aliquots were measured in triplicate using the ring method. The mean for each day was then recorded, and the standard deviations were calculated for each individual over the number of days (12 to 22) during which he collected.

Surface tension of urine samples from 9 volunteers were each measured, after which amphiphilic and hydrophobic solutes including bile salts were extracted from each urine sample using Sep-Pak $C_{18}$ cartridges (purchased from Waters Associates, U.K.) (8). The methanolic extracts were evaporated to dryness and were reconstituted in $0.1 \mathrm{~mol} / \mathrm{l}$ phosphate buffer $\mathrm{pH} 7.0$ to the same volume as the original sample and then surface tension was measured. 
Urine surface tensions were also measured on 4 fresh samples after which their corresponding bile salt levels were assayed employing a radioimmunoassay (RIA) method that measures conjugates of deoxycholate and cholate (Evans, S. E. (1984) personal communication).

Surface tensions of a further 30 fresh urine samples were measured followed by assaying their corresponding bile salt level using the Sterognost $3 \alpha-F l u$ enzymatic spectrofluorimetric method (Nyegaard and Co., Oslo) (9). The effect of dilution on surface tension of a 24 hour urine from a volunteer in the third trimester of pregnancy was also explored. Steroids were extracted as described previously (8) and then redissolved in increasing amounts of water commencing with the equivalent of a the 20-fold concentration of the original, serially diluted, until surfactant activity was equal to that of water (1 in 5000 parts of water).

\section{Results}

\section{Precision}

Parallel determinations using both ring detachment and blade immersion methods on 8 single surfaces (mean of 5 readings each) produced a correlation coefficient $(r)$ of $0.992(p=<0.01)$. Figure 1 shows the regression of ring method $(y)$ on blade method $(x) ; y=1.03 \times-1.94$. When 37 pairs of surfaces were measured using ring and blade methods the correlation between the two methods was excellent, there being only $0.01 \mathrm{mN} / \mathrm{m}$ difference in the mean values. The ring method gave a smaller standard deviation of $0.246 \mathrm{mN} / \mathrm{m}$ compared with the blade, $0.294 \mathrm{mN} / \mathrm{m}$. Paired sample ' $\mathrm{t}$ ' test showed a ' $\mathrm{t}$ ' value of 0.878 (difference not significant, $\mathrm{p}=<0.1$ ).

\section{Ageing of surface after pouring}

A total of 18 studies showed that the blade immersion technique could be performed more rapidly and the surface also reached an asymptotic state much more rapidly for a given time interval of measurement. The comparison of 30 second and 2 minute blade, and 2 minute ring measurements of a single urine sample is shown in figure 2 , and confirms that the blade surface equilibrates sooner, even if measurements are made every 30 seconds.

\section{Storage of urine}

There was less change in surface tension $( \pm 0.5$ $\mathrm{mN} / \mathrm{m}$ ) in 10 samples of urine stored at $20^{\circ} \mathrm{C}$, and measured in 24 hours, than in urine stored at $4^{\circ} \mathrm{C}$, or urine stored for longer periods of time at $20^{\circ} \mathrm{C}$ or $4{ }^{\circ} \mathrm{C}$. Frozen and rewarmed urine showed changes in surface tension of as much as \pm 4.0 and $-2.9 \mathrm{mN} / \mathrm{m}$ (six samples).

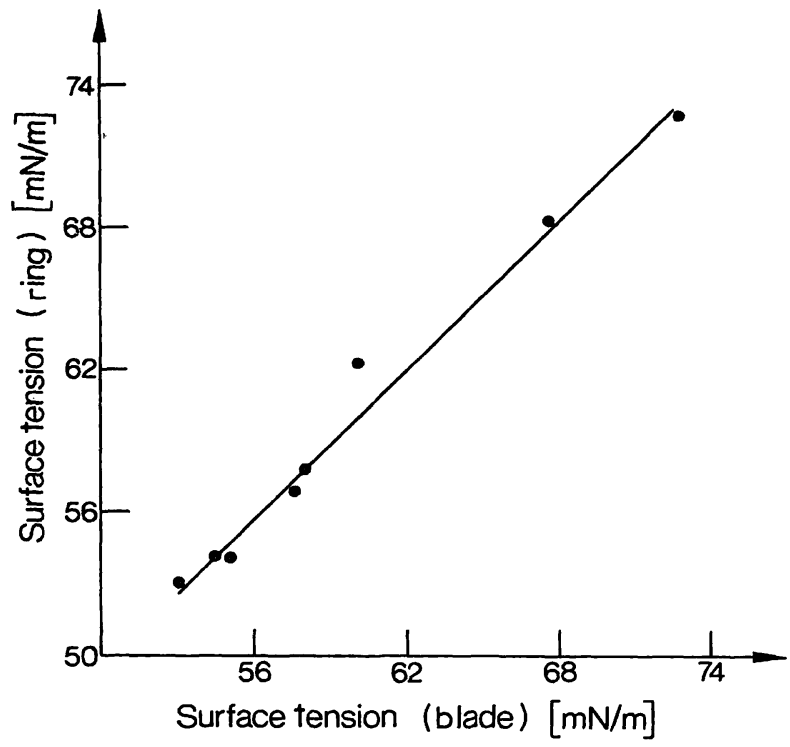

Fig. 1. Parallel determination in surface tension in seven urine samples and water control sample; blade immersion, ' $X$ ', and ring detachment, ' $Y$ ', methods. Regression line of ' $\mathrm{Y}$ ' on ' $\mathrm{X}$ '. $\mathrm{y}=1.03 \mathrm{x}-1.94$.

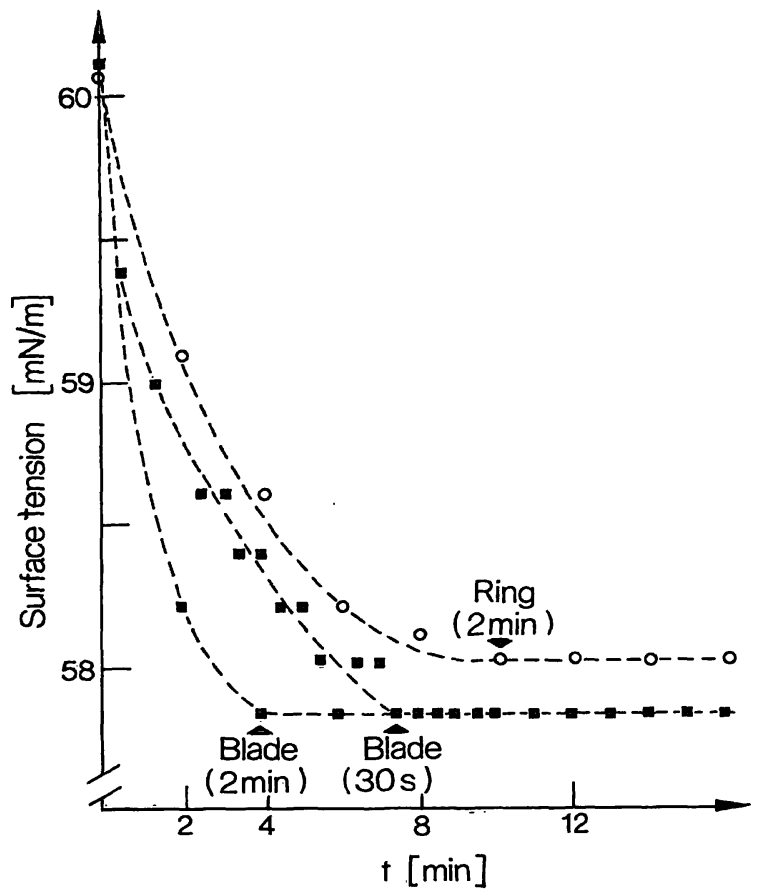

Fig. 2. Time dependent drop in surface tension to asymptotic state; a comparison of ring ( 2 minute interval) $(\mathrm{O}-\mathrm{O})$ and blade measurements ( 30 seconds and 2 minute intervals) (…ㅁ).

\section{Effect of temperature}

As with water, surfactant activity increased with rising temperature. Differences in surface tension with temperature change were greater in urine of high surface tension (i.e. $1 \mathrm{mN} / \mathrm{m}$ increase for $5^{\circ} \mathrm{C}$ change at 63 $\mathrm{mN} / \mathrm{m}$ at $20^{\circ} \mathrm{C}$ ), three times that of concentrated urine of $54 \mathrm{mN} / \mathrm{m}$ surface tension (fig. 3). The changes are linear and may be used to extrapolate degree of surfactant activity at body temperature. 


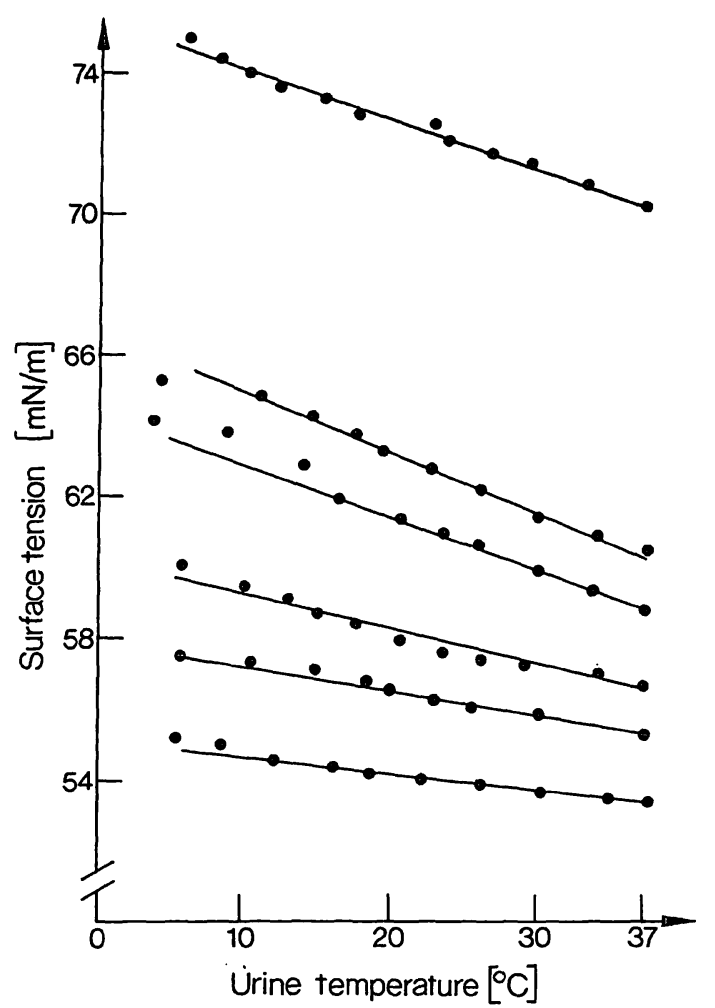

Fig. 3. Relationship between surface tension and temperature for water control and 5 urine samples of different surface tensions (blade method).

\section{Effect of dilution on surface tension}

Ring and blade methods demonstrate the same inverse linear relationship between log 10 concentration and surface tension. Dilution to 1 in 2 reduces surface tension by approximately $4 \mathrm{mN} / \mathrm{m}$ and 1 in 10 approximately $12 \mathrm{mN} / \mathrm{m}$. At dilutions greater than 1 in 100 surface tension becomes that of water (fig. 4).

\section{Effect of change of $\mathrm{pH}$}

Progressive alkalinisation of acid urine of different surface tensions did not alter surface tension between pH 6 and pH 9 (fig. 5).

\section{Effect of protein; electrolytes}

The addition of albumin as described in method section caused an initial rise in surface tension at all three concentrations of $1.5-2 \mathrm{mN} / \mathrm{m}$ at 5 minutes from preparation of samples, this slowly fell to equilibrate at the surface tension of the urine prior to addition of albumin within $20 \mathrm{~min}$ of preparing the surface. The major solutes in normal urine at maximal concentrations did not cause any significant change in surface tension (tab. 1) suggesting that these solutes play little part in determining surface activity of urine.

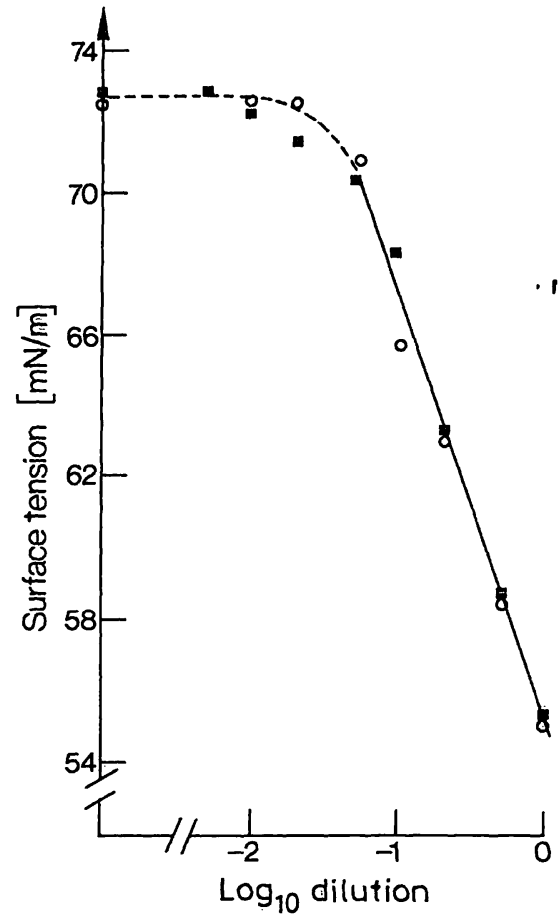

Fig. 4. Relationship between surface tension and $\log _{10}$ concentration of a single sample of urine using ring $(0)$ and blade ( $\mathbf{\square})$ methods.

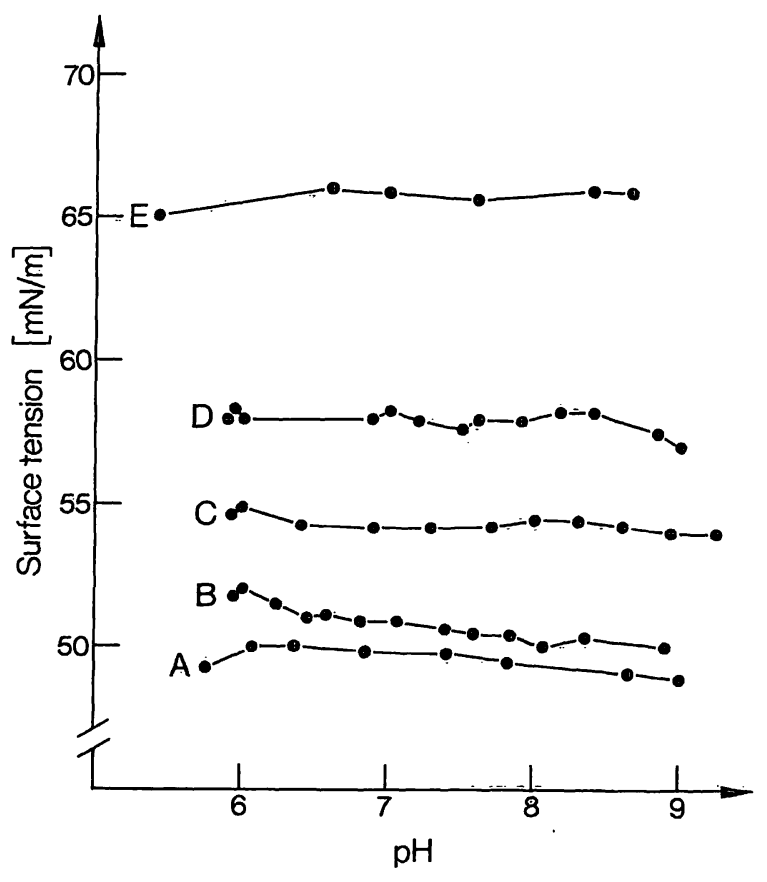

Fig. 5. Surface tension of 4 acid urine samples $(A-D)$ and water control (E) on alkalinizing with $0.89 \mathrm{~mol} / 1$ sodium hydroxide (blade method).

\section{$24 \mathrm{~h}$ volume corrected urine collections}

The 6 volunteers who collected $24 \mathrm{~h}$ urine saves for 12 or more days had mean $24 \mathrm{~h}$ surface tensions ranging from 55.7 to $62.0 \mathrm{mN} / \mathrm{m}$; mean for group $58.7 \mathrm{mN} / \mathrm{m}$. The highest and lowest individual mean surface tensions varied by \pm 1.5 standard deviations from group mean (tab. 2). 
Tab. 1. Surface tensions of common solutes found on human urine at maximum concentrations (ring method).

\begin{tabular}{lll}
\hline Solute & $\begin{array}{l}\text { Molarity } \\
(\mathrm{mol} / \mathrm{l})\end{array}$ & $\begin{array}{l}\text { Surface tension } \\
(\mathrm{mN} / \mathrm{m})\end{array}$ \\
\hline Water & - & 73.0 \\
Sodium chloride & 0.10 & 73.1 \\
Potassium chloride & 0.05 & 73.3 \\
Sodium bicarbonate & 0.50 & 73.1 \\
Ammonium bicarbonate & 0.02 & 72.7 \\
Magnesium chloride & 0.01 & 73.1 \\
Calcium hydroxide & 0.01 & 71.1 \\
Urea & 0.33 & 71.0 \\
Creatinine & 0.20 & 72.7 \\
Creatine & 0.10 & 73.3 \\
\hline
\end{tabular}

Tab. 2. Mean volume corrected 24 hour urine surface tensions in six subjects, over 12 or more days, with individual standard deviations.

\begin{tabular}{llll}
\hline Subject & $\begin{array}{l}\text { No. of } \\
\text { days }\end{array}$ & $\begin{array}{l}\text { Surface } \\
\text { tension } \\
(\mathrm{mN} / \mathrm{m})\end{array}$ & SD \\
$(\mathrm{mN} / \mathrm{m})$
\end{tabular}

Tab. 3. Surface tension of 9 fresh urine samples compared with reconstituted Sep-Pak $\mathrm{C}_{18}$ cartridge extracts to the same volume. Standard deviation of change of surface tension $=1.275 \mathrm{mN} / \mathrm{m}$. Arithmetic mean change $=0.022$. $\mathrm{mN} / \mathrm{m}, \mathrm{t}=0.05$ (not significant).

\begin{tabular}{lll}
\hline Subject & \multicolumn{2}{l}{ Surface tension $(\mathrm{mN} / \mathrm{m})$} \\
\cline { 2 - 3 } & Original urine & $\begin{array}{l}\text { Urine Sep-Pak } \mathrm{C}_{18} \\
\text { extract reconstituted }\end{array}$ \\
\hline 1 & 60.0 & 61.0 \\
2 & 56.8 & 59.2 \\
3 & 59.4 & 59.4 \\
4 & 58.4 & 58.6 \\
5 & 61.8 & 62.4 \\
6 & 62.8 & 61.0 \\
7 & 57.6 & 56.8 \\
8 & 57.4 & 56.0 \\
9 & 55.0 & 55.0 \\
\hline
\end{tabular}

\section{Bile salt and surface tension studies}

Surface tension values of urine samples from 9 volunteers were similar to values of their corresponding Sep-Pak $C_{18}$ extracts, $t=0.05$ (tab. 3). It is therefore possible that the surfactant activity of urine was due to amphiphilic and hydrophobic solutes including bile salts. The data on the quantitation of bile salt levels in urine utilizing RIA indicated an inverse relationship between urine surface tension and conjugated bile salts of deoxycholate and cholate with correlation coefficient of $-0.91, p<0.01$ (fig. 6). Further quantitation of bile salt concentrations in urine using a spectrofluorimetric assay again revealed an inverse relationship between total bile salt concentrations and surface tension values with a correlation coefficient of -0.60 that was highly significant $(t=-3.66$, $\mathrm{n}=30, \mathrm{p}<0.001$ ) (fig. 7). These results suggest that bile salts are probably responsible for most of the surfactant activity of urine. Figure 8 shows the total steroidal extract from a 24 hour urine sample of a pregnant patient when plotted as surface tension against logarithm concentration of bile salts have a slope of $-12 \mathrm{mN} / \mathrm{m} \cdot \mu \mathrm{mol}$, and the slope of normal human urine was $-11.8 \mathrm{mN} / \mathrm{m} \cdot \mu \mathrm{mol}$ similarly diluted. The surface tension value of the extract 49.8 $\mathrm{mN} / \mathrm{m}$ was $3.6 \mathrm{mN} / \mathrm{m}$ less than the surface tension of the original urine sample at the same value. This inverse relationship existed from 70 to $54 \mathrm{mN} / \mathrm{m}$ for both normal urine (fig. 4) and for the reconstituted extract from the pregnant patient. These findings are in agreement with the data reported by Kratohvil \& Delli Colli (10) with slopes of -12 for conjugated bile salts of deoxycholate, from which they calculated a

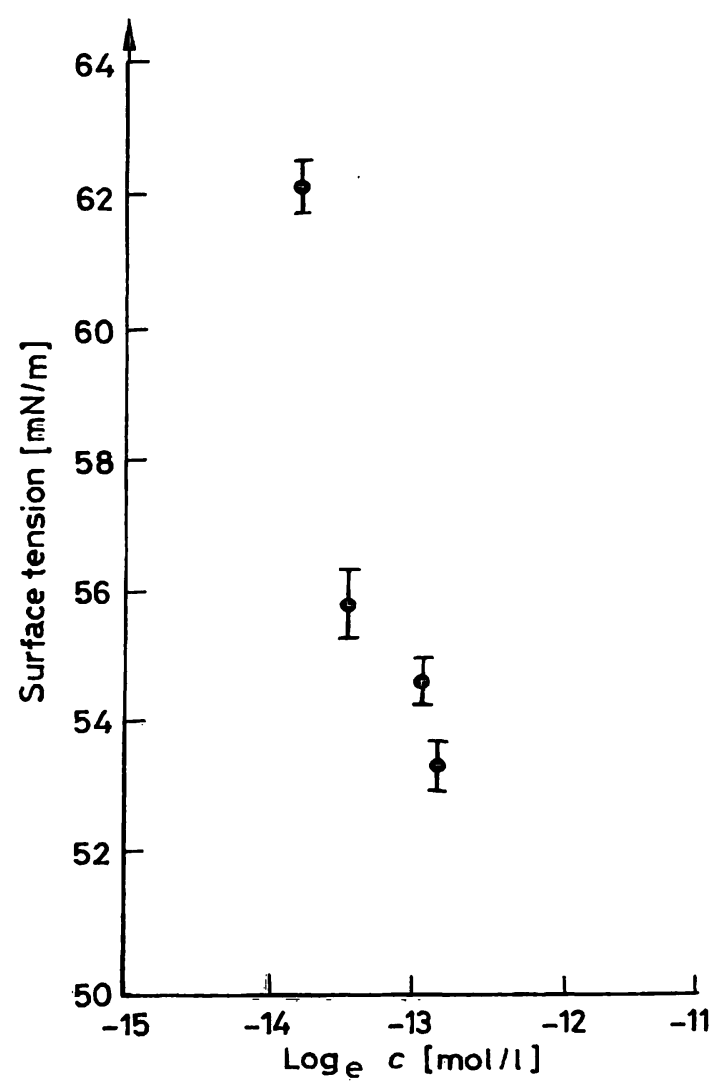

Fig. 6. Surface tension as a function of bile salt concentration of 4 urine samples measured by RIA (conjugates of deoxycholate and cholate). Correlation coefficient $-0.91 ; p<0.01$

$\log _{e} 10^{-5} \mathrm{~mol} / \mathrm{l}=-11.5 ; \log _{e} 10^{-6} \mathrm{~mol} / \mathrm{l}=-13.8$ 


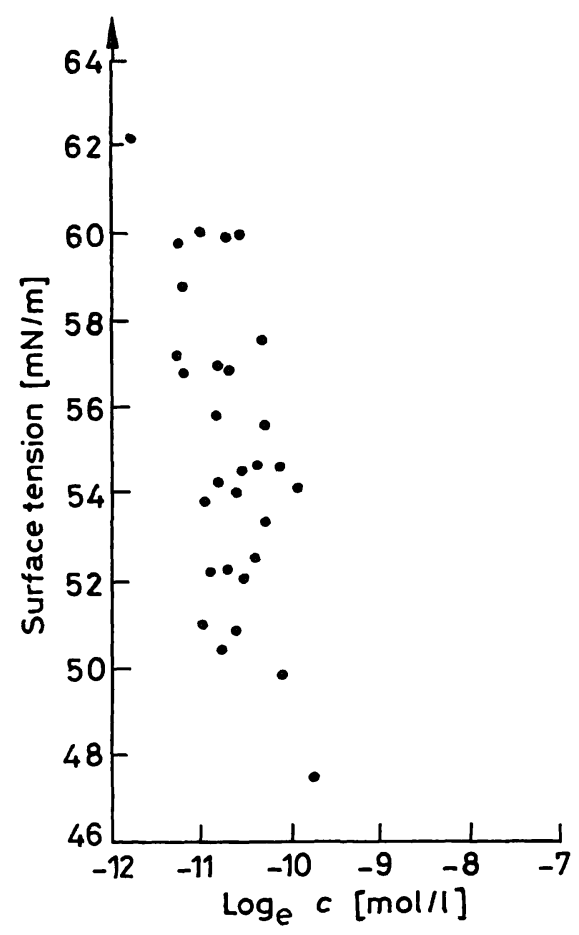

Fig. 7. Surface tension of 30 urine samples as a function of bile salt concentration measured by an enzymatic fluorometric method. Correlation coefficient -0.60 , $\mathrm{t}=-3.66, \mathrm{p}=<0.001$.

$\log _{e} 10^{-4} \mathrm{~mol} / 1=-9.2 ; \log _{e} 10^{-5} \mathrm{~mol} / \mathrm{l}=-11.5$

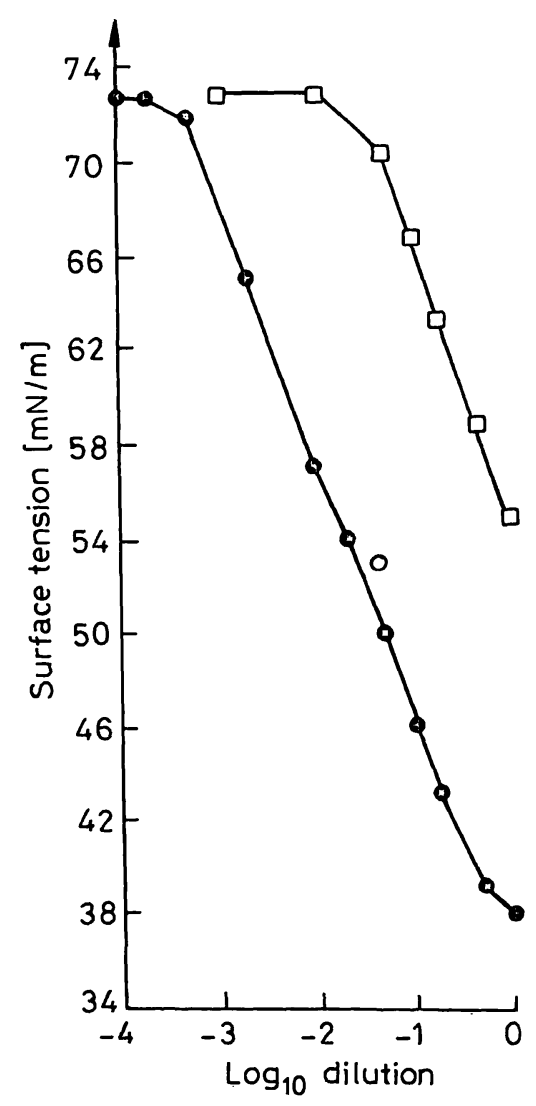

Fig. 8. Surface tension of increasing dilutions of reconsituted urine extract, from subject in 3rd trimester of pregnancy - - Dilution profile.

o Original surface tension before extraction.

$\square-\square$ Dilution profile of normal urine sample (fig. 4). molecular surface area of $90 \AA^{2}$. The total urinary bile acid extract contained some electrolyte and according to Pethica (11) the surface excess concentration $(\Gamma)$ of the bile salt may be calculated by Gibbs absorption isotherm equation, $\Gamma=-(1 / \mathrm{RT})(\mathrm{d} \gamma / \ln c)$ where $\mathrm{R}=8.31 \mathrm{Joules} / \mathrm{mol} \cdot \mathrm{Kelvin}, \mathrm{T}=$ absolute temperature, $\gamma=$ surface tension, and $\ln c=$ natural logarithm concentrations. Employing the Gibbs equation as well as $\AA=1 / \Gamma N$ where $\AA=$ area in $\AA$ ingstrom units and $\mathrm{N}=$ Avogardro's number, it is possible to determine the surface area occupied by a surfactant molecule lying on a surface (12). On this basis we calculate the surface area of the urinary surfactant molecule to be $79 \AA^{2}$ which compared favourably with the surface area of $85 \AA^{2}$ occupied by the steroid nucleus lying at an interface calculated using a Langmuir trough method (13).

\section{Discussion}

This study shows that human urine surface tension may be measured accurately, quickly and simply using either the Wilhelmy blade immersion or DuNouy ring detachment methods. Provided urine is fresh, at constant temperature, of $\mathrm{pH} 6-9$, and the surface is bubble-free and has been allowed to equilibrate for over 10 minutes before measurements are made, accurate and reproducible results may be obtained. There is a linear inverse relationship between log urine concentrations and surface tension. We agree with Hahn ((1984), personal communication) that the blade immersion technique is to be preferred generally, although larger amounts of liquid (about $10 \mathrm{ml}$ ) are required.

Healthy urine is usually protein and glucose-free but we noted prolongation of ageing in samples of urine to which albumin was added in concentration between 1 and $10 \mathrm{~g} / 1$. The measurement of surface tension of native serum proteins in aqueous media has been investigated by Absolom et al. (14), who showed that human serum albumin with concentrations between 3.5 and $55 \mathrm{~g} / \mathrm{l}$, which itself has a surface tension of $\simeq 70.3 \mathrm{mN} / \mathrm{m}$ measured by other methods, re-orientates at an air/liquid interface to a much more hydrophobic tertiary configuration with much lower surface tension $(\simeq 50 \mathrm{mN} / \mathrm{m})$. We suspect that at a urine air interface where albumin is present, bile acids and albumin compete for the surface, but eventually the inherently more surface active bile salts displace the albumin, so apart from increasing the ageing time of the surface, albumin in concentrations up to $10 \mathrm{~g} / \mathrm{l}$, does not influence urinary surface tension, nor do maximal concentration of urinary solutes. 
Urine surface tension varies between $70 \mathrm{mN} / \mathrm{m}$ and $48 \mathrm{mN} / \mathrm{m}$ in health, depending partly on concentration. Although dilute urine generally has a high surface tension and concentrated urine has a low surface tension, some variation still remains between different individuals where 24 hour urine collections are diluted up to a standard volume (tab. 2). A difference of over $6 \mathrm{mN} / \mathrm{m}$ between the individual whose mean surface tension was lowest and the one with the highest surface tension represents at least a twofold difference in surface active agent concentration in the bulk urine. Furthermore, we have noted postprandial reduction in surface tension of volume corrected urines in some subjects, suggesting an increase in excretion of surface active agents which are probably bile salts. Serum bile acids are significantly raised postprandially in healthy controls (15). The total daily excretion of bile acids in urine correlates with the degree of cholestasis in patients with liver disease (16). Our urine extraction and bile salt quantitation studies indicate an inverse relationship between urine surface tension and bile salt concentration. Data $(2.09 \mu \mathrm{mol} / 1$ for conjugated cholic acid) reported by Jorg-Wildgrube et al. (17) for assay of bile salts in a 24 hour urinary extraction in healthy humans using RIA was in the same range as that found in this study (fig. 6). Thus we may use measurements of surface tension to compare varying renal excretion of surface active agent. Thus the surfactants responsible for surface tension changes in physiological urine are steroids probably the conjugates, the most surface active of the bile salts (18). As 24 hour measurements of other urinary steroids reflect increased or reduced endocrine activity, so 24 hour measurement of urine surface tension may reflect increased or reduced surfactant activity of the blood. Such increase or reduction in surfactant activity might be important in the deposition or reabsorption of lipid in vessel walls, that is, in the pathogenesis of atheroma.

Although the measurements of surface tension of blood is relatively simple, different investigators have found widely differing mean surface tensions for human populations. Using the same ring detachment method at $20^{\circ} \mathrm{C}$, Mottaghy \& Hahn (2) obtained a serum surface tension of $46 \mathrm{mN} / \mathrm{m}$, Kunzel (19), 59.2 $\mathrm{mN} / \mathrm{m}$ and Lewin $51.0 \mathrm{mN} / \mathrm{m}(20)$. In addition to the surface active constituents of blood itself, anticoagulants and possibly contamination with silicone lubricant in syringes may contribute to the surface, and therefore surface tension of blood.

By contrast, urine surface tension may be measured by a simple standardised method, and varies in health over a measurable range. Indirectly it could provide some indication of surfactant activity in blood, in health. The fact that different individuals produce 24 hour urine samples, which when standardised differ in surface tension, requires further investigation.

\section{Acknowledgement}

We gratefully acknowledge financial support from the West Midlands Regional Health Authority Committee, the Coventry and Warwickshire Postgraduate Medical Centre Research Fund, and the Rudolf Friedlaender Memorial Fund for General Practice. C. O. M. is supported by the Medical Research Council of U.K.

We thank Dr. John Padday, Interface Science Laboratory, Kodak Ltd., for his encouragement and advice, and for fashioning the platinum blades, and Professor $T$. $P$. Whitehead for advice.

We especially thank the Partners and Staff at Red Roofs Surgery who assisted in many ways, Mrs. Aline Stinton for her skill and patience in making the surface tension measurements, Mr. W. Germaine for statistical advice, Mrs. I. Arnold, Miss. J. Wormington and Miss. M. Towle for typing the manuscript.

\section{References}

1. DuNouy, P. L. (1926) Surface Equilibria of Biological Organic Colloids, pp. 35-70, American Chemical Society, Monograph series, J. J. Little and Ives Co., New York.

2. Mottaghy, K. \& Hahn, A. (1981) J. Clin. Chem. Clin. Biochem. 19, 267-271.

3. Padday, J. F. (1969) The measurement of surface tension. Vol. 1, pp. $101-149$, Surface and Colloid Science. Col. E. Matejevic and F. Eirich, New York.

4. Padday, J. F. \& Russel, D. R. (1960) J. Colloid Sci. 15, $503-511$.

5. Abribat, M. \& Dognon, A. (1939) Compt. Rend. Acad. Sci. Paris. 208, $1881-1882$.

6. Hay, M. (1886) Test for bile acids. In: 'A Text Book of Human Physiology' 2nd. edit. (Landois, A. \& Stirling, A., eds.) London.

7. Harkins, W. D. \& Jordan, H. F. (1930) J. American Chem. Soc. $52,1751-1756$.

8. Whitney, J. O. \& Thaler, M. M. (1980) J. Liq. Chromatogr. $3,545-556$.

9. Hedenborg, G., Norman, A. \& Samuelson, K. (1984) Scand. J. Clin. Lab. Invest. 44, $761-763$.

10. Kratohvil, J. P. \& DelliColli, H. T. (1968) Canad. J. Biochem. 46, 945-953.

11. Pethica, B. A. (1954) Trans. Farad. Soc. 50, 413-421.

12. Mysels, K. A. (1984) Hepatology 45,80 S- 84 S.

13. Ekwall, P. \& Ekholm, R. (1957) Monolayers of Bile Acids pp. 23-30, Proc. 2nd. Inter. Congr. Surface Activity, Butterworths London.

14. Absolom, D. R., Van Oss, C. J., Zingg, W. \& Neumann, A. W. (1981) Biochim. Biophys. Acta 670, 74-78.

15. Pennington, C. R., Ross, P. E. \& Boucher, I. A. D. (1977) Gut 18, 903-908.

16. Back, P. (1973) Clin. Chim. Acta 44, 199-207. 
17. Jorg Wildgrube, H., Stockhausen, H., Metz, P., Mauritz, G. \& Madawi, R. (1983) Clin. Chem. 29, 494-498.

18. Roda, A., Hofman, A. F. \& Mysels, K. J. (1983) J. Biol Chem. 258, 6362-6370.
19. Kunzel, O. (1941) Ergbn. Inn. Med. Kinderheilk. 60, 565656.

20. Lewin, S. (1972) Brit. J. Haematol. 22, $561-566$.

Dr. G. H. B. Martin

Red Roofs Surgery

31 Coton Road

Nuneaton, Warks.

CV11 5TW

U.K. 